\title{
Gotta Go, Mom's Calling: Dolphin (Tursiops truncatus) Mothers Use Individually Distinctive Acoustic Signals To Call Their Calves
}

\author{
Stan A. Kuczaj II ${ }^{1 *}$, Holli C. Eskelinen², Brittany L. Jones ${ }^{1,2}$, and Jill L. Borger-Turner ${ }^{2,3}$ \\ ${ }^{1}$ University of Southern Mississippi \\ ${ }^{2}$ Dolphins Plus \\ ${ }^{3}$ University of Miami \\ *Corresponding author (Email: s.kuczaj@usm.edu)
}

Citation-Kuczaj, S. A. II, Eskelinen, H. C., Jones, B. L., \& Borger-Turner, J. L. (2015). Gotta go, Mom's calling: Dolphin (Tursiops truncatus) mothers use individually distinctive acoustic signals to call their calves. Animal Behavior and Cognition, 2(1), 88-95. doi: 10.12966/abc.02.07.2015

\begin{abstract}
Dolphin calves often wander away from their mothers, which can compromise their safety and survival. Mothers can retrieve their calves by actively pursuing them or by signaling their wandering calves to return. However, little is known about the retrieval techniques employed by mothers in specific calf recall contexts. We experimentally investigated maternal calf retrieval methods by assessing behavioral and acoustic strategies employed by three Atlantic bottlenose dolphin mothers to elicit their calf's return in a controlled, non-threatening setting. Three mothers were asked to retrieve their calves on cue in this setting, and could do so however they chose. Mothers were much more likely to use energetically less costly acoustic signals than physical retrievals. Each mother produced individually distinctive calls that incorporated the mother's signature whistle but often also involved additional whistles and clicks. The dolphin mothers' use of individually distinctive calls to request a calf's return is consistent with the notion that other dolphins can distinguish such calls and provides additional support for the notion that dolphin communication is flexible rather than fixed.
\end{abstract}

Keywords - Dolphin, Mother-calf, Acoustic signals, Communication

Dolphin calves, like the young of many species, are vulnerable to predation (Fearnbach, Durban, Parsons, \& Claridge, 2012; Mann \& Barnett, 1999; Mann \& Smuts, 1998), as well as both inter- and intraspecies aggression (Herzing \& Johnson, 1997; Kaplan, Lentell, \& Lange, 2009; Robinson, 2014; Smolker, Mann, \& Smuts, 1993). Maintaining proximity to the mother decreases such risks for a calf, and young calves and mothers are often found close to one another (e.g., Kuczaj \& Winship, in press). Mothers of young calves bear the primary responsibility for proximity maintenance and typically achieve this by either herding or following calves (Hill, Greer, Solangi, \& Kuczaj, 2007). As calves mature, they assume more responsibility for remaining close to the mother or returning to her following separations (Chirighin, 1987; Hill et al., 2007; Mann \& Smuts, 1999; Reid, Mann, Weiner, \& Hecker, 1995).

Given the dangers dolphin calves may be exposed to during separations from their mothers, one might expect mothers and calves to rarely be apart. Although mothers and calves are often found in close proximity, a calf's curiosity and propensity to seek out social interactions with other dolphins may result in separations. As calves develop, regular separations are considered a sign of vitality and increased independence (Kuczaj \& Winship, in press; Mann \& Watson-Capps, 2005). When calves stray from their mothers, mothers can elect to end a separation by pursuing and herding the calf to the desired location, an energetically expensive process. In contrast, the mother may use a more economical approach by 
acoustically signaling her calf to return. McBride and Kritzler (1951) first described this strategy in bottlenose dolphins when they observed a mother, in resting position, whistling until her calf returned to her, at which point the whistling stopped. Acoustic signals that function as contact calls appear throughout the animal kingdom (Insley, 2001; Jouventin, Aubin, \& Lengagne, 1999; Kondo \& Watanabe, 2009; Trillmich, 1981; Weiß, Ladich, Spong, \& Symonds; 2006), dolphins use individually specific whistle contours, termed "signature whistles," as contact calls (Caldwell \& Caldwell, 1965, 1968; Caldwell, Caldwell, \& Tyack, 1990; Fripp \& Tyack, 2008; Janik \& Slater, 1998; Kuczaj, 2014; Smolker et al., 1993).

A calf may begin to learn its mother's signature whistle in utero (Kuczaj \& Winship, in press; Mello \& Amundin, 2005). Towards the end of the gestational period, dolphin mothers increase the rate with which they produce their signature whistle, a phenomenon that persists in the days immediately following parturition (Fripp \& Tyack, 2008; Gnone \& Moriconi, 2009; Mello \& Amundin, 2005). This increase in maternal signature whistle production both before and immediately after birth may facilitate the calf's association of a particular whistle with the mother and may play an important role in the development of the mother-calf bond (Kuczaj \& Winship, in press; Mello \& Amundin, 2005). Although a calf's ability to discriminate and recognize its mother's signature whistle likely contributes to the calf's ability to locate its mother when they are separated, much of the work on dolphin mother-calf separations and reunions has focused on the role of the calf as the initiator of the reunions (Fripp et al., 2005; Mann \& Smuts, 1999; McCowan \& Reiss, 1995; Smolker et al., 1993). Consequently, little is known about the methods mothers employ to reunite with their calves, which likely depend on both context and differences in maternal style (Hill et al., 2007). Additionally, while many have described the use of signature whistles in contexts of separation and isolation (e.g., Caldwell \& Caldwell, 1965; Janik \& Slater, 1998), the use of signature whistles in facilitating reunion between mother and calf has rarely been studied. The use of signature whistles increases when mothers and calves are separated and whistles are more likely to be produced the greater the distance between mother and calf (Smolker et al., 1993). In the Smolker et al. study, calves were more likely to produce signature whistles during separations than were mothers, a calf's whistles perhaps signaling its desire to reunite with the mother. But little is known about the signals produced by mothers when they want their calf to return. McCowan and Reiss (1995) described a thunk sound that that mothers emit during calf retrievals. These low frequency pulsed sounds seem to successfully end a mother-calf separation but are typically followed by aggressive and disciplinary behaviors displayed by the adult female towards the calf.

In order to investigate the strategies mothers exercise to regain proximity to their calves, Atlantic bottlenose dolphin (Tursiops truncatus) mothers in a captive facility were asked to retrieve their absent calves on cue and in the absence of obvious threats to either the mothers or the calves. Mothers could elect to retrieve their calves using physical, acoustic, or a combination of acoustic and physical retrieval techniques. This is the first experimental investigation of dolphin mother calf retrievals and provides a detailed behavioral and acoustic analysis of the methods employed by various mothers to achieve a desired outcome.

\section{Method}

Three T. truncatus mother-calf pairs were housed in one of two enclosures (mean depth $4.5 \mathrm{~m}$, area 3,000 $\mathrm{m}^{2}$ each) at Dolphins Plus and Island Dolphin Care in Key Largo, Florida (Table 1). Mothers were asked to retrieve their respective calves following a visual cue delivered by a trainer. Mothers could employ any method to retrieve their calves, since the contingency for reinforcement was non-specific and only required the calf's return to the mother's location. Thus, mothers could physically retrieve their calves, signal their calves to return acoustically, or produce acoustic signals while physically retrieving the calf. 
Table 1

Study Subjects at Dolphins Plus and Island Dolphin Care Including Data Collection Dates, Facility, and Lagoon Cohorts

\begin{tabular}{llll}
\hline Mother & Calf & Facility & \multicolumn{1}{c}{ Conspecifics in Enclosure } \\
\hline Ding & BB & Dolphins Plus & Sarah, Grace, Jessica, Zoe, Fiji \\
Sarah & Grace & Island Dolphin Care & Ding, Julie, Little Bit, Samantha \\
Squirt & Lotus & Island Dolphin Care & Fiji, Bob, Bella, Jessica, Elvis, Nica \\
\hline
\end{tabular}

Each mother participated in a minimum of 20 trials (Sarah, $N=41$; Squirt, $N=29$; Ding, $N=20$ ) during the first two years of their respective calf's life. Experimental trials were initiated only after the focal mother and calf were stationed together at a platform for a minimum of two minutes. During the first six months of a calf's life, trials were executed opportunistically when the calf spontaneously ventured at least five meters away from the mother. After six months of age, the calf could be sent away on cue to another location in the habitat to facilitate the separation and initiate the start of a trial. In both scenarios, a trial was initiated when a trainer signaled the mother to retrieve her calf. This signal was only given when all other dolphins within the enclosure were with their trainers and had their heads above the surface of the water, where they remained for the duration of the trial. This was necessary to ensure that the target mother and/or calf produced the underwater calls recorded. Successful retrievals were scored as physical (i.e., mother left station to retrieve calf), acoustic (i.e., mother emitted whistle and/or clicks), or physical retrievals with acoustic signals. A successful calf retrieval sequence, regardless of type, typically lasted between $5-30 \mathrm{~s}$, and never exceeded one minute.

All trials were video and audio recorded using Canon G9 and G12 digital cameras equipped with underwater housings. Each camera sampled sound at $46 \mathrm{kHz}$, resulting in a Nyquist frequency cut off of $23 \mathrm{kHz}$.

Acoustic data were analyzed using Raven Pro 1.4, acoustic analysis software from Cornell University. Raven spectrogram parameters were set at Window type, Hann, and Size, 512 samples (512 DFT), with a $50 \%$ overlap and 256 hop size and a $3 \mathrm{db}$ filter bandwidth.

Calls associated with retrievals were broadly identified as whistles (i.e., frequency modulated, narrowband signals), clicks (i.e., broadband pulsed signals), or a combination of both, and call contours were further analyzed to characterize specific whistle types. Inclusion criteria for contours were that the contour be emitted more than one time throughout the dataset. Individual signature whistles (Caldwell \& Caldwell, 1965) were identified using an extensive sound catalog (2009 - 2014) for the T. truncatus populations at Dolphins Plus and Island Dolphin Care. The sound catalog included observer confirmed sounds collected under a variety of environmental conditions and behavioral contexts (e.g., foraging, parturition, copulation, courtship, communal swimming, animal introductions, husbandry procedures/transports), excluding calf retrieval calls.

\section{Results}

Mothers were more likely to successfully retrieve their calves than to fail to do so (binomial test, $M=88 \%, p<0.05$ ) (Figure 1) and were significantly more likely to use an acoustic signal (i.e., whistles, clicks, or a combination of whistles and clicks) $(81.48 \%)$ than a physical or combined acoustic and physical retrieval to recall their calves $\left(\chi^{2}(2, N=79)=83.11, p<0.05\right.$; see Figure 2$)$. Two of the mothers (Squirt and Ding) never engaged in physical retrievals, but instead consistently opted to use acoustic signals to recall their calves. Sarah was also more likely to use acoustic signals but combined physical retrievals with acoustic calls in approximately one third of her trials. Sarah was also the only mother to physically retrieve her calf without calling, but this was a rare event $(N=2)$. 


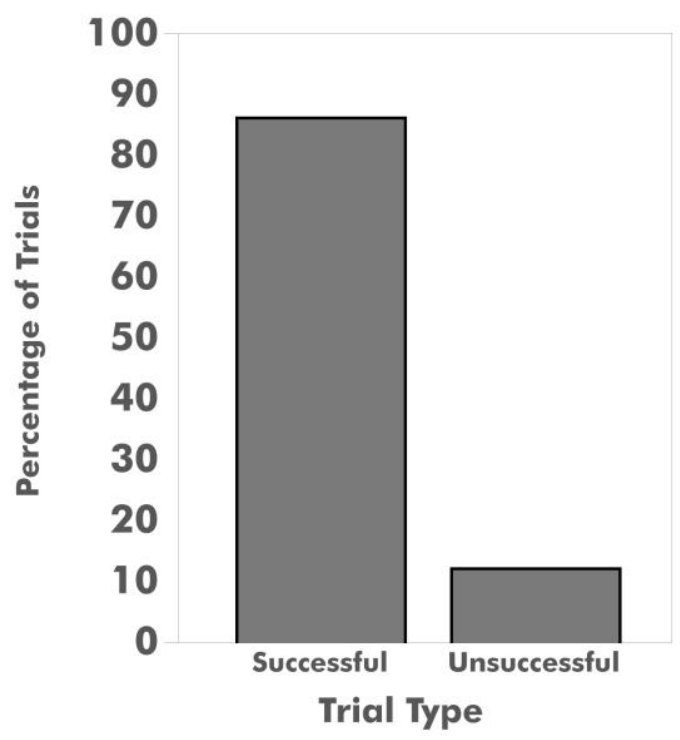

Figure 1. Percentage of trials during which mothers successfully or unsuccessfully called their respective calves.

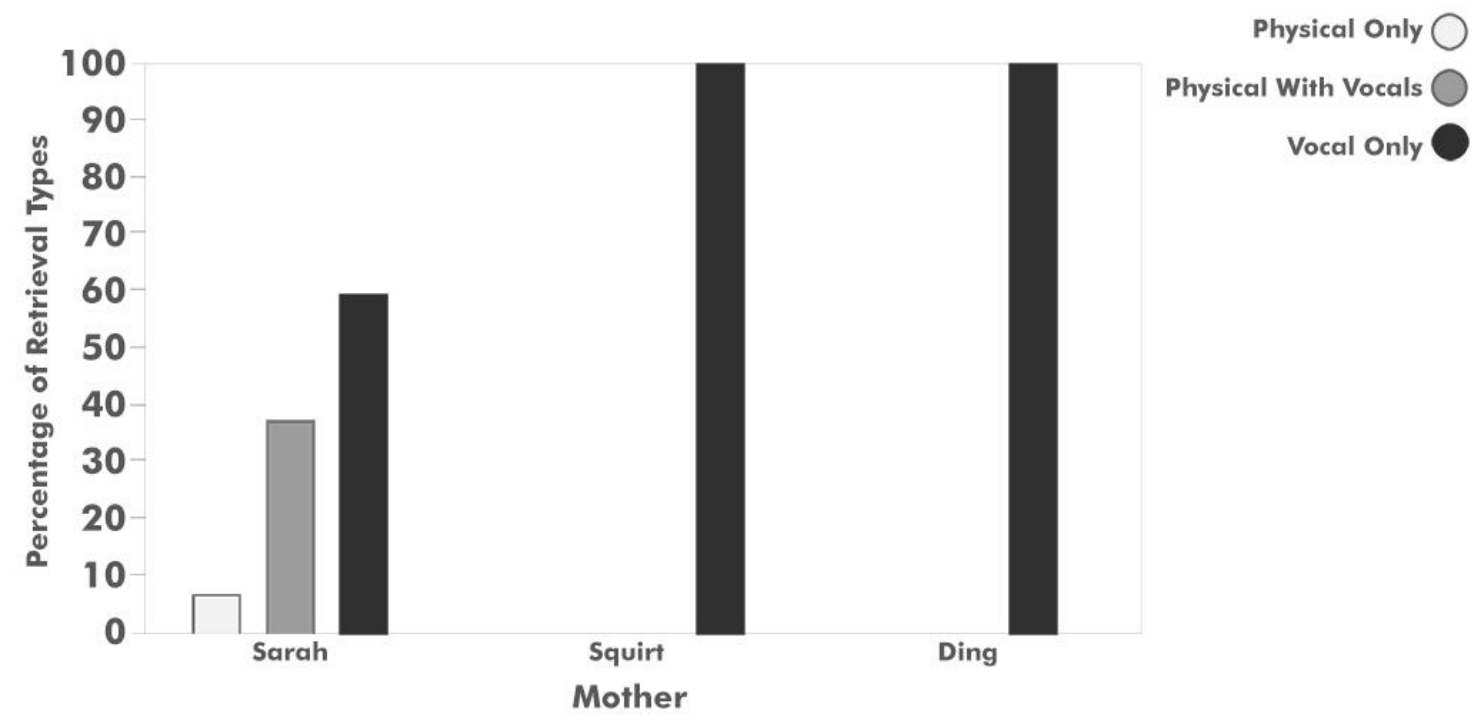

Figure 2. Relative percentage of retrieval types each mother used to recall her calf.

Six distinct whistle contours were recorded during calf retrievals, each mother producing two distinct contours in the calf recall context (Figures $3 \& 4$ ). Ding produced whistles A and B but never produced whistles $\mathrm{C}-\mathrm{F}$. Sarah produced whistles $\mathrm{C}$ and D but never produced whistles A, B, E, or F. Squirt produced whistles $\mathrm{E}$ and $\mathrm{F}$ but never produced whistles $\mathrm{A}-\mathrm{D}$.

Each of the mothers used her signature whistle in the calf recall context (Sarah: Type C; Squirt: Type E; Ding: Type A). However, each mother often used her signature whistle and/or a secondary whistle, sometimes in combination with clicks, to retrieve her calf. Sarah and Ding were significantly more likely to use their signature whistles than their secondary whistle in the calf recall context (Sarah: $t(37.65)=3.27, p<0.05$; Ding: $t(32.83)=3.57, p<0.05)$. Squirt used both her signature whistle and her secondary whistle during calf recalls but without a significant preference. Furthermore, Sarah and Squirt's secondary whistles were not present in the acoustic catalogue, which included whistles recorded across 
many behavioral contexts, suggesting that these calls may be specific to the calf retrieval process for these two mothers.
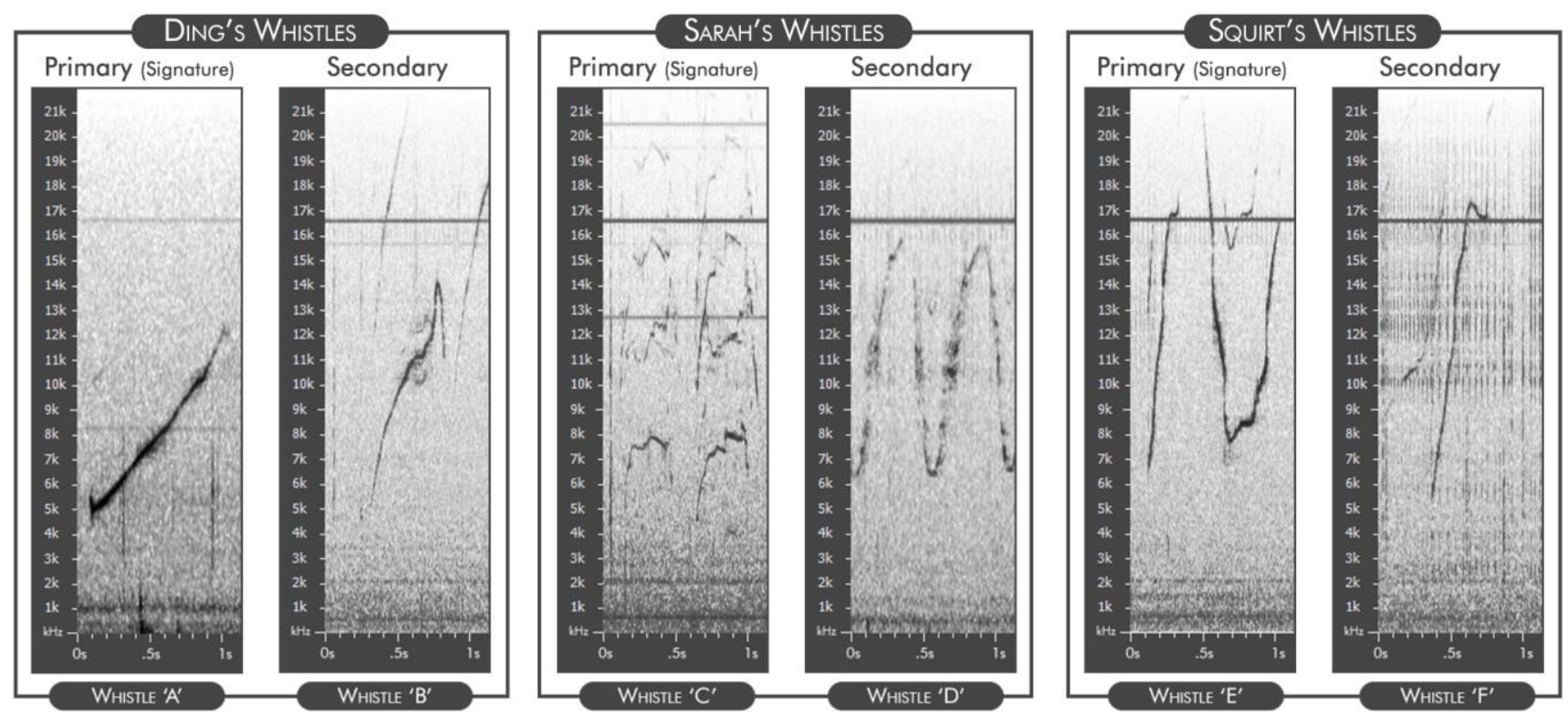

Figure 3. Spectrograms of six distinct whistle contours recorded during all call calf retrievals. Each mother produced only two contours to call their respective calves, identified as Signature Whistle (Ding: A, Sarah: C, Squirt: E) and Secondary Whistle (Ding: B, Sarah: D, Squirt: F). Sound sampling at $46 \mathrm{kHz}$, Nyquist frequency cut off at $23 \mathrm{kHz}$, with a consistent apparatus sound artifact at $\sim 17 \mathrm{kHz}$.
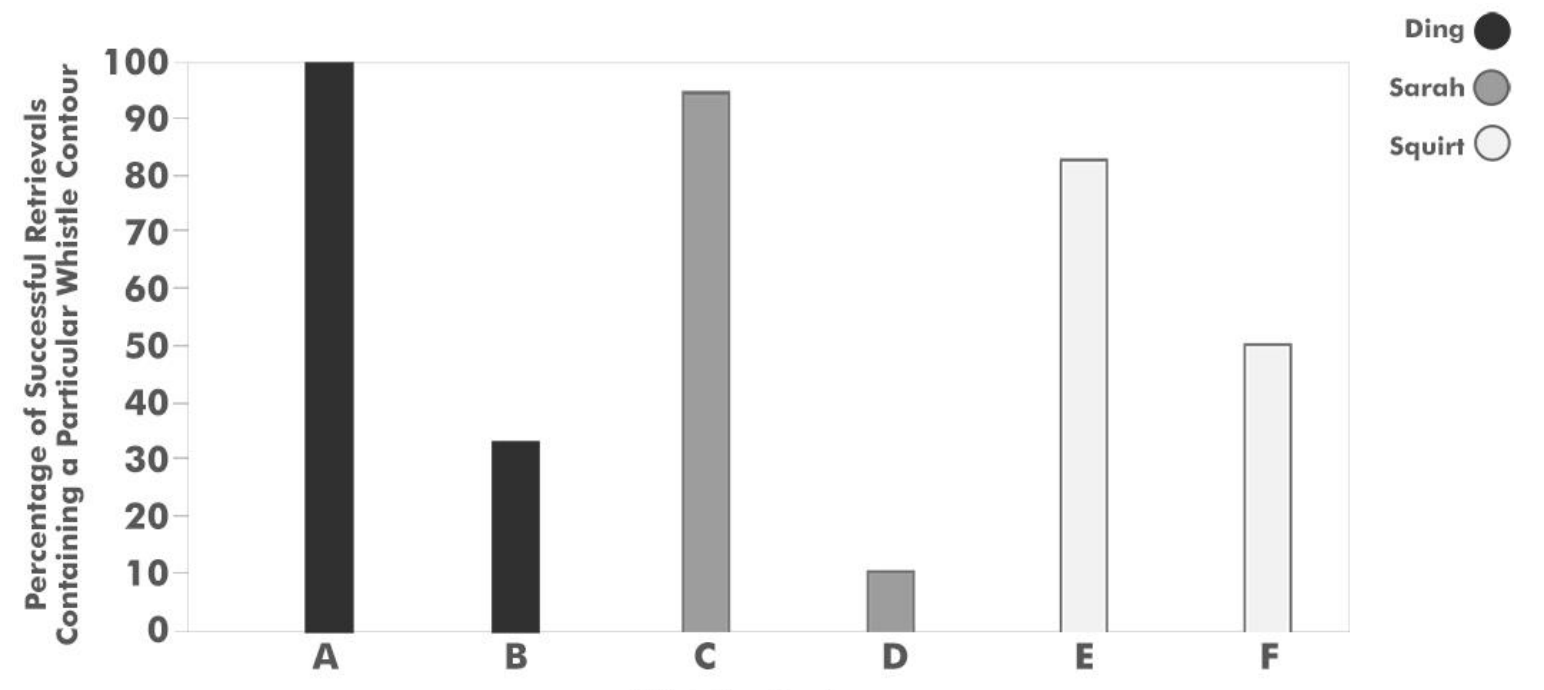

Whistle Contour

Figure 4. Percentage of successful retrievals containing a specific whistle contour used by one of the mothers in the calf retrieval context.

Mothers were significantly more likely to use a combination of whistles and clicks than either call type alone $\left(\chi^{2}(2, N=79)=10.81, p<0.05\right)$, though there were distinct differences among mothers (Figure 5). Ding was most likely to use whistle/click combinations $\left(\chi^{2}(2, N=18)=10.33, p<0.05\right)$, next most likely to use whistles alone, but never used clicks without whistles when asked to retrieve her calf. 
Sarah was most likely to use whistle/click combinations $\left(\chi^{2}(2, N=36)=7.167, p<0.05\right)$, next most likely to use clicks alone, and least likely to use whistles alone to retrieve her calf. Squirt retrieved her calf using clicks alone the majority of the time $\left(\chi^{2}(2, N=25)=22.64, p<0.05\right)$ but also used whistle/click combinations. However, she never used only whistles to recall her calf.
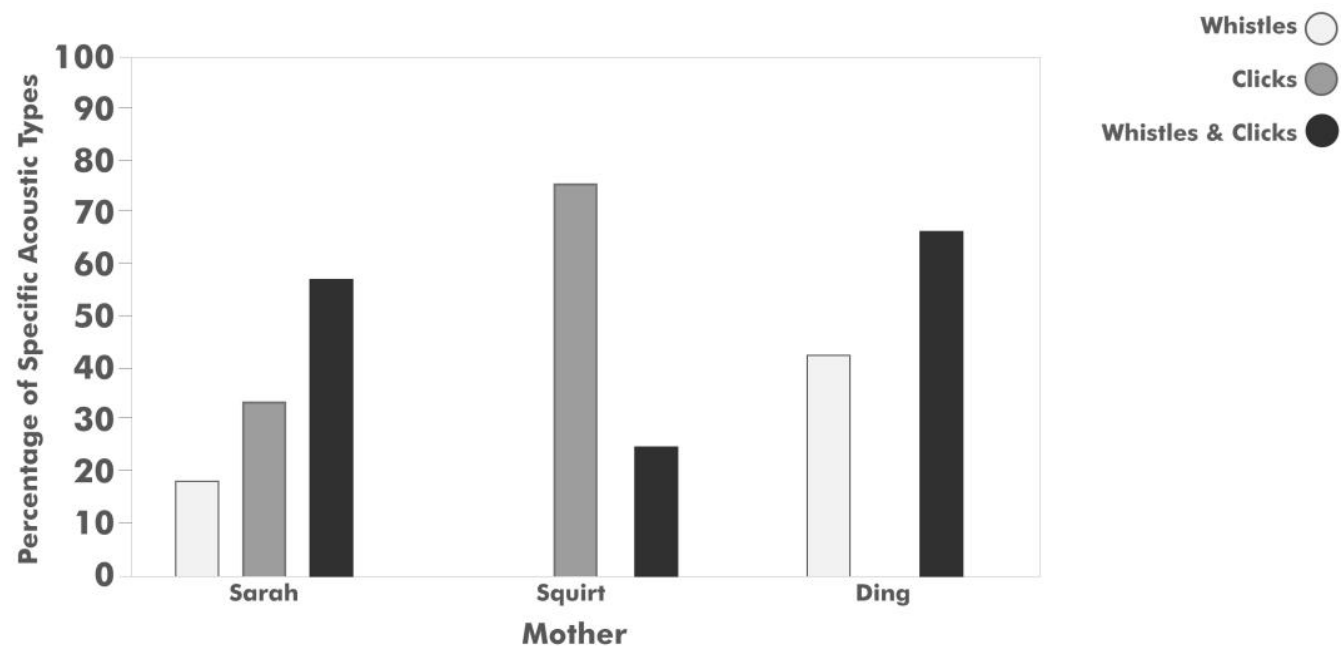

Figure 5. Relative percentage of specific acoustic types (whistles, clicks, or a combination of whistles and clicks) used by each mother in the calf retrieval context.

\section{Discussion}

Mothers were overwhelmingly successful in retrieving their calves when requested to do so on cue in a non-urgent context. They were significantly more likely to use acoustic signals when asked to retrieve their calves than to pursue their calf and herd it to the requested location. The predominant and selective use of acoustic signals to recall calves is consistent with the notion that such signals are an important and efficient form of communication among dolphins (Janik \& Sayigh, 2013; Kuczaj, 2014; Tyack \& Sayigh, 1997).

The alarm and contact calls of some species are stereotyped in the sense that members of a given species or group use the same calls (Marler, 1975; Marler, Evans, \& Hauser; 1992; Seyfarth, Cheney, \& Marler, 1980). However, some species are able to modify their calls to provide more specific information (Fichtel, Perry, \& Groslouis, 2005; Seyfarth et al., 2010). The dolphin mothers we studied used distinctly different calls to retrieve their calves, demonstrating individual variation in the use of communication signals within the retrieval context. This finding demonstrates that the signals used to retrieve calves are neither universal across dolphins nor innately specified. Most often, the signals consisted of whistles, with each mother using two unique whistles in the calf recall context. For each mother, one of the main whistle contours used in successfully recalling the calf was her signature whistle, which supports the hypothesis that a mother's signature whistle facilitates proximity maintenance throughout the first two years of a calf's life (see also Fripp \& Tyack, 2008; Kuczaj, 2014; Kuczaj \& Winship, in press; Mann \& Smuts, 1998; Smolker et al., 1993).

Each mother used her signature whistle and/or a secondary whistle, sometimes in combination with clicks, to retrieve her calf. However, mothers differed in the extent to which they used each type of acoustic form to recall their calves. Sarah and Squirt's secondary whistles were not recorded in any other behavioral context represented in the sound catalog, suggesting that these calls may be specific to the calf retrieval process. Given that neither of these secondary whistles was associated with all successful retrievals, their precise function is uncertain, but it is possible that they were used to convey additional information about location, emotional state, and/or to emphasize the mother's desire for the calf to return. Additionally, all of the mothers used whistles and click combinations during some of their calf retrievals, 
but Ding never used clicks without whistles to recall her calf. These individual differences reflect unique acoustic strategies employed by each mother to achieve a specific outcome. Nonetheless, all mothers were significantly more likely to use acoustic calls rather than physical retrievals to reunite with their calves and, as such, were selectively utilizing the retrieval method with the lowest energetic cost.

The role of whistles in mother-calf acoustic interactions has been the subject of numerous studies (Fripp et al., 2005: Fripp \& Tyack, 2008; Gnone et al., 2001: Gnone \& Moriconi, 2009; Mann \& Smuts, 1999; Mello \& Amundin, 2005; Smolker et al., 1993), but our findings suggest that an understanding of the combined use of different sounds may be critical to studies of dolphin communication. Clicks, historically associated with object identification, localization and navigation ( $\mathrm{Au}, 1993)$, were commonly used in combination with whistles during calf retrievals in this study. In some cases, a mother's use of clicks alone resulted in the calf's return. Although the communicative function of clicks in this context is not yet clear, it may be that clicks are used to signal additional information beyond that encoded by the mothers' whistles. McCowan and Reiss (1995) described a pulsed emission recorded during a calf retrieval context, although the thunk described varied greatly (e.g., max frequency thunks $=5.5 \mathrm{kHz}$, duration) from the click train emissions observed in this study. This suggests that the thunk is used predominantly during urgent calf retrievals, or contexts that resulted in disciplinary action, which further supports the notion that context and urgency likely affects the strategies and call types used by the mothers. Thus, future studies should evaluate recall signals and retrieval strategies during naturally occurring stressful situations, as well as spontaneous separations and reunions in non-threatening contexts. In this study, dolphin mothers successfully recalled their calves using signature whistles, secondary whistles, and clicks, which demonstrates the plasticity and flexibility of the dolphin acoustic communication system (Kuczaj, 2014; Kuczaj \& Makecha, 2008) as well as our limited understanding of dolphin signals.

\section{References}

Caldwell, M. C., \& Caldwell, D. K. (1965). Individualized whistle contours in bottle-nose dolphins (Tursiops truncatus). Nature, 207, 434-435.

Caldwell, M. C., \& Caldwell, D. K. (1968). Vocalization of naïve captive dolphins in small groups. Science, 159, $1121-1123$.

Caldwell, M. C., Caldwell, D. K., \& Tyack, P. L. (1990). Review of the signature-whistle hypothesis for the Atlantic bottlenose dolphin. In S. Leatherwood \& R. R. Reeves (Eds.), The bottlenose dolphin (pp. 199-234). San Diego, CA: Academic Press.

Chirighin, L. (1987). Mother-calf spatial relationships and calf development in the captive bottlenose dolphin (Tursiops truncatus). Aquatic Mammals, 13, 5-15.

Fearnbach, H., Durban, J., Parsons, K., \& Claridge, D. (2012). Photographic mark-recapture analysis of local dynamics within an open population of dolphins. Ecological Applications, 22, $1689-1700$.

Fichtel, C., Perry, S., \& Groslouis, J. (2005). Alarm calls of white-faced capuchin monkeys: An acoustic analysis. Animal Behaviour, 70, 165-176.

Fripp, D., Owen, C., Quintana-Rizzo, E., Shapiro, A., Buckstaff, K., Jankowski, K., \& Wells, R. (2005). Bottlenose dolphin (Tursiops truncatus) calves appear to model their signature whistles on the signature whistles of community members. Animal Cognition, 8, 17-26.

Fripp, D., \& Tyack, P. L. (2008). Post-partum whistle production in bottlenose dolphins. Marine Mammal Science, 24, 479-502.

Gnone, G., \& Moriconi, T. (2009). Use and function of distinctive whistle-like signals in bottlenose dolphin (Tursiops truncatus) mother-calf pair. In A. G. Pearce \& L. M. Correa (Eds.), Dolphins: Anatomy, behavior, and threats (pp. 149-167). New York: Nova Science Publishers, Inc.

Gnone, G., Pavan, G., Manca, S., Benoldi, C., Bonsignori, B., \& Manghi, M. (2001). Signature whistle, acoustic imprinting and individual recognition in a bottlenose dolphin mother-calf pair in captivity. Natura, 90, 4756.

Herzing, D. L., \& Johnson. C. M. (1997). Interspecific interactions between Atlantic spotted dolphins (Stenella frontalis) and bottlenose dolphins (Tursiops truncatus) in the Bahamas, 1975-1995. Aquatic Mammals, 23, 85-89. 
Hill, H. M., Greer, T., Solangi, M., \& Kuczaj, S. A. II. (2007). All mothers are not the same: Maternal styles in bottlenose dolphins (Tursiops truncatus). International Journal of Comparative Psychology, 20, 35-54.

Insley, S. J. (2001). Mother-offspring vocal recognition in northern fur seals is mutual but asymmetrical. Animal Behaviour, 61, 129-137.

Janik, V. M., \& Sayigh, L. S. (2013). Communication in bottlenose dolphins: 50 years of signature whistle research. Journal of Comparative Physiology A, 199(6), 479-489.

Janik, V. M., \& Slater, P. J. B. (1998). Context-specific use suggests that bottlenose dolphin signature whistles are cohesion calls. Animals Behaviour, 56, 829-838.

Jouventin, P., Aubin, T., \& Lengagne, T. (1999). Finding a parent in a king penguin colony: The acoustic system of individual recognition. Animal Behaviour, 57, 1175-1183.

Kondo, N., \& Watanabe, S. (2009). Contact calls: Information and social function. Japanese Psychological Research, 51, 197-208.

Kuczaj, S. A. II. (2014). Language learning in cetaceans. In P. Brooks, V. Kempe, \& J. Golsoon (Eds.), Encyclopedia of language development (pp. 328-331). Thousand Oaks, CA: Sage.

Kuczaj, S. A. II, \& Makecha, R. (2008). The role of play in the evolution and ontogeny of contextually flexible communication. In U. Griebel \& K. Oller (Eds.), Evolution of communicative flexibility: Complexity, creativity, and adaptability in human and animal communication (pp. 253-277). Cambridge, MA: MIT Press.

Kuczaj, S. A. II., \& Winship, K. (in press). How do dolphin calves make sense of their world? In D. Herzing \& C. Johnson (Eds.), Dolphin communication and cognition. Cambridge, MA: MIT Press.

Mann, J., \& Smuts, B. (1998). Natal attraction: Allomaternal care and mother-infant separations in wild bottlenose dolphins. Animal Behavior, 55, 1097-113.

Mann, J., \& Smuts, B. (1999). Behavioral development in wild bottlenose dolphin newborns (Tursiops). Behaviour, $136,529-566$.

Mann, J., \& Watson-Capps, J. (2005). Surviving at sea: Ecological and behavioral predictors of calf mortality in Indian Ocean bottlenose dolphins, Tursiops sp. Animal Behaviour, 69, 899-909.

Marler, P. (1975). On the origin of speech from animal sounds. In J. Kavanagh \& J. Cutting (Eds.), The role of speech in language (pp. 11-40). Cambridge, MA: MIT Press.

Marler, P., Evans, C. S., \& Hauser, M. D. (1992). Animal signals: Motivational, referential, or both? In H. Papousek, U. Jurgens, \& M. Papousek (Eds.), Nonverbal vocal communication. New York: Cambridge University Press.

McBride, A. E., \& Kritzler, H. (1951). Observations on pregnancy, parturition, and post-natal behavior in the bottlenose dolphin. Journal of Mammalogy, 32, 215-266.

McCowan, B., \& Reiss, D. (1995). Whistle contour development in captive-born infant bottlenose dolphins (Tursiops truncatus): Role of learning. Journal of Comparative Psychology, 109, 242-260.

Mello, I., \& Amundin, M. (2005). Whistle production pre-and post-partum in bottlenose dolphins (Tursiops truncatus) in human care. Aquatic Mammals, 31, 169-175.

Seyfarth, R. M., Cheney, D. L., Bergman, T., Fischer, J., Zuberbuhler, K., \& Hammerschmidt, K. (2010). The central importance of information in studies of animal communication. Animal Behaviour, 80, 3-8.

Seyfarth, R. M., Cheney, D. L., \& Marler, P. (1980). Monkey responses to three different alarm calls: Evidence for predator classification and semantic communication. Science, 210, 801-803.

Smolker, R. A., Mann, J., \& Smuts, B. B. (1993). Use of signature whistles during separations and reunions by wild bottlenose dolphin mothers and infants. Behavioral Ecology and Sociobiology, 33, 393-402.

Trillmich, F. (1981). Mutual mother-pup recognition in Galapagos fur seals and sea lions: Cues used and functional significance. Behaviour 78, 21-42.

Weiß, B. M., Ladich, F., Spong, P., \& Symonds, H. (2006). Vocal behavior of resident killer whale matrilines with newborn calves: The role of family signatures. The Journal of the Acoustical Society of America, 119, 627635. 